\title{
Regenerative medicine in lower limb reconstruction
}

\author{
Josephine K McEwan ${ }^{1}$, Howard C Tribe ${ }^{1}$, Neal Jacobs², Nicholas Hancock ${ }^{3}$, Amir A Qureshi \\ Douglas G Dunlop**,3 \& Richard OC Oreffo*,1 \\ ${ }^{1}$ Bone \& Joint Research Group, Centre for Human Development, Stem Cell \& Regeneration, Institute of Developmental Sciences, \\ University of Southampton, Tremona Road, Southampton SO16 6YD, UK \\ ${ }^{2}$ Salisbury NHS Foundation Trust, Salisbury, Wiltshire, UK \\ ${ }^{3}$ Trauma \& Orthopaedic Department, University Hospital Southampton, Southampton, UK \\ *Author for correspondence: richard.oreffo@soton.ac.uk \\ **Author for correspondence: doug.dunlop@uhs.nhs.uk
}

Bone is a highly specialized connective tissue and has a rare quality as one of the few tissues that can repair without a scar to regain pre-injury structure and function. Despite the excellent healing capacity of bone, tumor, infection, trauma and surgery can lead to significant bone loss requiring skeletal augmentation. Bone loss in the lower limb poses a complex clinical problem, requiring reconstructive techniques to restore form and function. In the past, amputation may have been the only option; however, there is now an array of reconstructive possibilities and cellular therapies available to salvage a limb. In this review, we will evaluate current applications of bone tissue engineering techniques in limb reconstruction and identify potential strategies for future work.

First draft submitted: 1 February 2018; Accepted for publication: 15 May 2018; Published online: 9 July 2018

Keywords: biomaterials $\bullet$ critical-sized defects $\bullet$ lower limb reconstruction $\bullet$ nonunion $\bullet$ orthopedics $\bullet$ regenerative medicine $\bullet$ stem cells $\bullet$ trauma

\section{Clinical need \\ Background}

Major trauma is the leading cause of deaths in children and adults aged under 46 years old [1]. Major trauma describes serious injuries, often multiple, from which there is a high risk of death or disability. Major trauma can also be defined as patients with an Injury Severity Score greater than 15 [2], which is associated with a mortality of $10 \%$ [3]. The most common mechanism resulting in major trauma in the UK and USA is a road traffic accident. Other mechanisms include a fall from a height and physical violence. Major trauma also includes any single injury that is so complex that it exceeds the capabilities or expertise of a receiving trauma hospital. As such, open fractures, particularly those with bone defects, and or skin tissue loss, may constitute a major trauma and represent a limb threatening injury that could have life changing consequences.

\section{Lower limb reconstruction}

The complex management of severe lower limb injuries has led to the development of lower limb reconstruction as a subspecialty field within orthopedic surgery. Lower limb reconstruction aims to tackle clinical problems such as nonunion, limb deformities and critical-sized bone defects (CSDs) due to trauma, tumor or infection (http://blrs.org.uk/). A CSD relates to bone loss that will not heal within the patient's lifetime, generally accepted to be bone loss of greater than 1.5-times the diameter of the diaphysis of the bone [4].

The management of complex lower limb injuries and the sequelae of these injuries require a range of different surgical skills to restore form and function of a limb. Regenerative medicine aims to repair tissues through stem cell therapy, tissue engineering and manipulation of molecular biology to regenerate diseased or damaged tissue. Evaluating the role of regenerative medicine in limb reconstruction requires an understanding of the basic science of fracture healing, the current treatment modalities available and novel strategies that have already been implemented. 


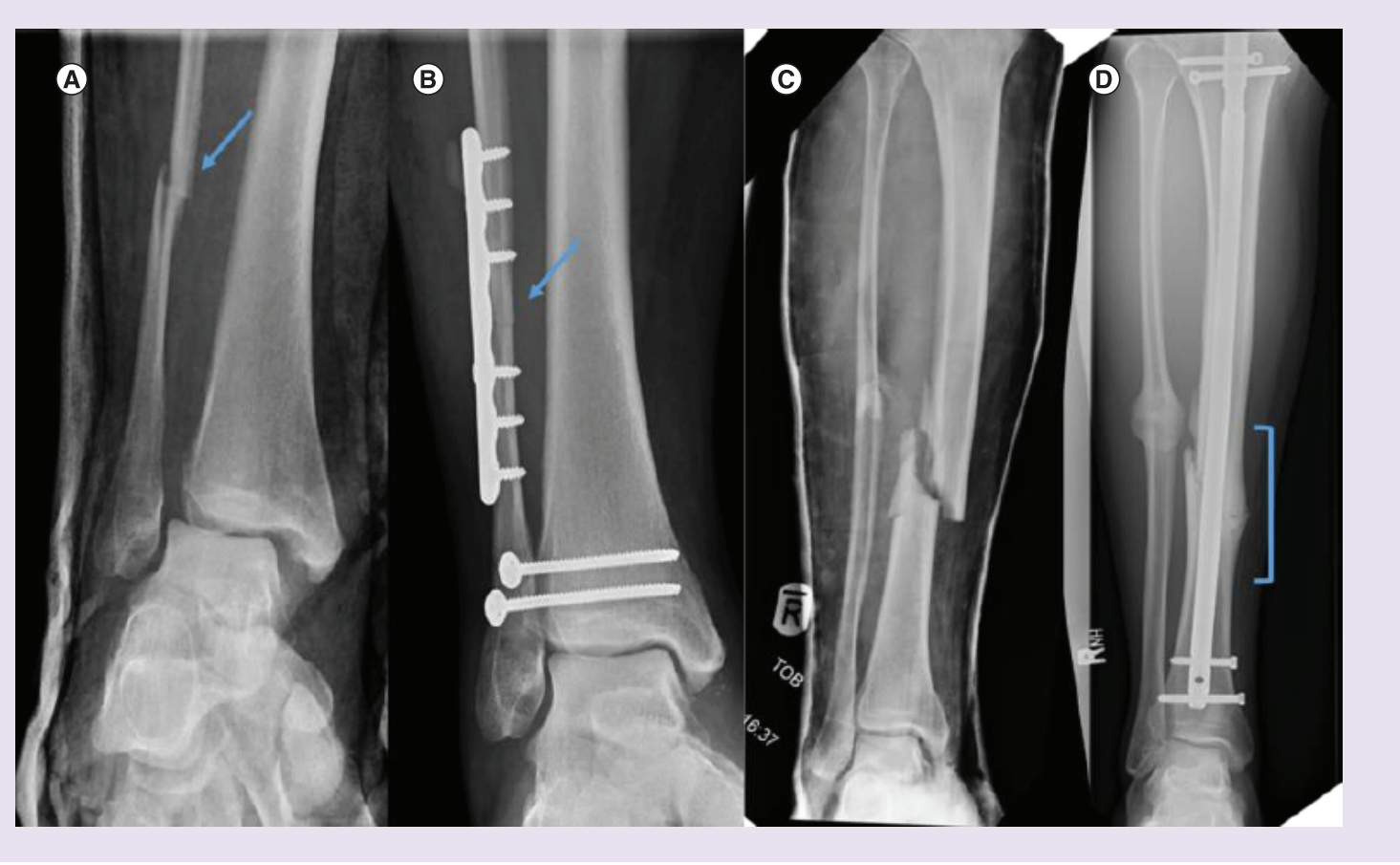

Figure 1. Primary and secondary bone healing. (A) Fibula fracture (see arrow). (B) Fibula fracture healed by primary bone healing following open reduction internal fixation (see arrow). (C) Tibia and fibula fracture. (D) Tibia and fibula fracture healed by secondary bone healing with callus formation (see bracket).

\section{Bone healing}

If bone is subjected to excessive force (stress or strain), it will fracture. Bone has an exceptional ability to heal and remodel, enabling restoration of physical and biological properties after an injury [5]. This clinical observation contributes to the rationale supporting the concept of a postnatal stem cell population residing within the bone marrow [6], which is responsible for bone regeneration and repair. Bone heals according to both the mechanical and biological environment in which the fracture exists [7], and as such, can be affected and influenced [5]. Recognizing the biological processes occurring in the context of the mechanical situation is crucial to understanding clinical scenarios and directing treatment strategies.

\section{Primary (direct) fracture healing}

Primary bone healing requires anatomical reduction of fracture fragments, which only usually occurs following operative open reduction and internal fixation (Figure 1A \& B). Mechanically, this equates to a fracture gap of less than $10 \mu \mathrm{m}$ and less than $5 \%$ strain at the fracture site, which will lead to intramembranous ossification [8]. Under these conditions, osteoclasts and osteoblasts are able to bridge the fracture gap and form a cutting cone in which the osteoclasts form the head of the cone to resorb bone, and the osteoblasts follow depositing new bone matrix.

\section{Secondary (indirect) fracture healing}

More commonly, bone healing is secondary bone healing; comprising of both intramembranous and endochondral bone formation and consists of four interlinked stages [9]. Following a bony injury, a hematoma forms which has osteogenic and angiogenic potential to create the environment for optimum healing [10]. The fracture hematoma and subsequent inflammation release numerous signaling molecules (IL-1, IL-6, TNF- $\alpha$, FGF, IGF, PDGF, VEGF and TGF- $\beta$ superfamily members) [5] that coordinate a tightly organized cascade of events to result in vascularized bone formation [11]. The fracture hematoma between the bone ends provides a mesh of fibrin that acts as an osteoconductive scaffold for soft cartilaginous callus to form. The soft callus then undergoes vascularization and calcification, with subsequent remodeling to resume normal bone architecture [12]. Clinically, endochondral ossification can be achieved by casting or functional bracing, or using operative techniques that allow micromotion at the fracture site (Figure 1C \& D) to stimulate bone union $[8,13]$. 


\section{Nonunion}

A fracture that fails to heal is described as a nonunion. There is no globally agreed clinical or radiographic definition of a nonunion [14]. A generalized clinical description is the cessation of progressive fracture repair after 6 months, although there are many influencing factors that may affect the time scale in which a fracture is expected to heal. For example, high energy open fractures will take longer to heal than simple, low energy fractures, and patient age and bone site also play a role. An early definition of nonunion was reported by Weber and Cech in 1973, in which nonunions were categorized as active or inactive [15]. Nonunions are often categorized as hypertrophic or atrophic according to the volume of callus present on radiographic imaging. Hypertrophic nonunions are thought to represent biologically active vascular bone that lacks mechanical stability at the fracture site, which impedes progression to bony union. Atrophic nonunions are often thought to represent biologically inactive bone, with impaired vascularity [16] that are unable to heal despite the appropriate mechanical environment. However, it has been demonstrated that atrophic nonunions can be well vascularized [17] and a study that analyzed biopsies from hypertrophic and atrophic nonunion sites found there was no difference in the vascularity between the two groups [18]. Both forms of nonunion signify a serious complication and cause substantial morbidity to the patient; potentially requiring lengthy treatments, re-operation, restricted mobility and resultant poor quality of life. In addition, there is the economic impact of the cost of treatment to consider, which has been shown to range from approximately $£ 6700-80,000$ per nonunion [19], as well as the patient's sick leave from work [20].

Tibial diaphyseal fractures are the most common diaphyseal fractures encountered in orthopedics in adults [21] and may present as an isolated injury or as part of a polytrauma scenario. There is a high rate of tibial nonunion; the incidence of delayed union or nonunion for all fractures is estimated at $5-10 \%$ [22], yet for open tibial fractures, nonunion rates can rise to $60 \%$ [23]. The high prevalence of tibial nonunion is likely due to the lack of a soft tissue overlying the bone, contributing to the tibia's vulnerability to injury, as well as a relative decreased vascularity, compared with other long bones, leading to a subsequent high rate of impaired healing [24]. The management of complex tibial fractures and nonunion creates a significant clinical challenge requiring reconstructive strategies for successful treatment.

\section{Lower limb reconstruction}

\section{Surgical strategies}

Bone graft

Using autologous bone graft (ABG) or synthetic bone substitution to promote healing and fusion remains the simplest form of bone tissue engineering adopted in day to day practice [25]. The ideal graft material should provide three key properties: osteoconduction, osteoinduction and osteogenic capacity [25]. In addition, the graft material should be nonimmunogenic, nontoxic and degrade within an appropriate time frame [26]. Furthermore, in the austere environment, at least within the UK and the National Health Service, cost-effectiveness of new materials is also a pertinent consideration [27]. ABG is often considered the 'gold standard' graft material; however, harvest surgery has risks of operative complications, such as nerve injury, vascular injury, hernia formation and pain. Furthermore, the volume of graft harvested can be limited [28].

In the treatment of tibial nonunion, bone grafting and compression fixation has traditionally been the hallmark treatment of choice [16]. Yet this strategy is not always adequate in the management of CSDs, which require large volumes of bone with mechanical stability. Autologous bone harvest from the iliac crest can yield up to $20-50 \mathrm{~cm}^{3}$ of graft [29]; however, tibial defect volumes can range from 3.1 to $122.0 \mathrm{~cm}^{3}$ [30]. Vascularized bone grafts (typically rib or fibula transfer) are a highly specialized form of ABGs, illustrated in Figure 2. Vascularized bone grafts require microsurgical expertise and are technically demanding procedures, associated with nonunion rates reported from 5 to $23 \%$ [31,32], graft fracture rates of $15-20 \%$ [32,33] and lack of graft hypertrophy [32]. There are higher rates of complications using vascularized bone graft transfers in the lower limb compared with the upper limb [34], potentially as a consequence of greater load bearing and graft size mismatch, which is less of an issue in the upper limb.

Periosteal free flaps, originally popularized for treating avascular necrosis of the scaphoid by swinging tissue from the distal radius, can also be harvested from the medial femoral condyle, as a further microsurgical technique used in nonunion management. The periosteum and outer cortex is extracted on a vascular pedicle, the graft can then be shaped as required and the vascular supply is inset into the recipient site [35]. However, periosteal free flaps are primarily used for small bone defects $<3 \mathrm{~cm}[36,37]$, rather than CSDs, and do not offer mechanical support. An 


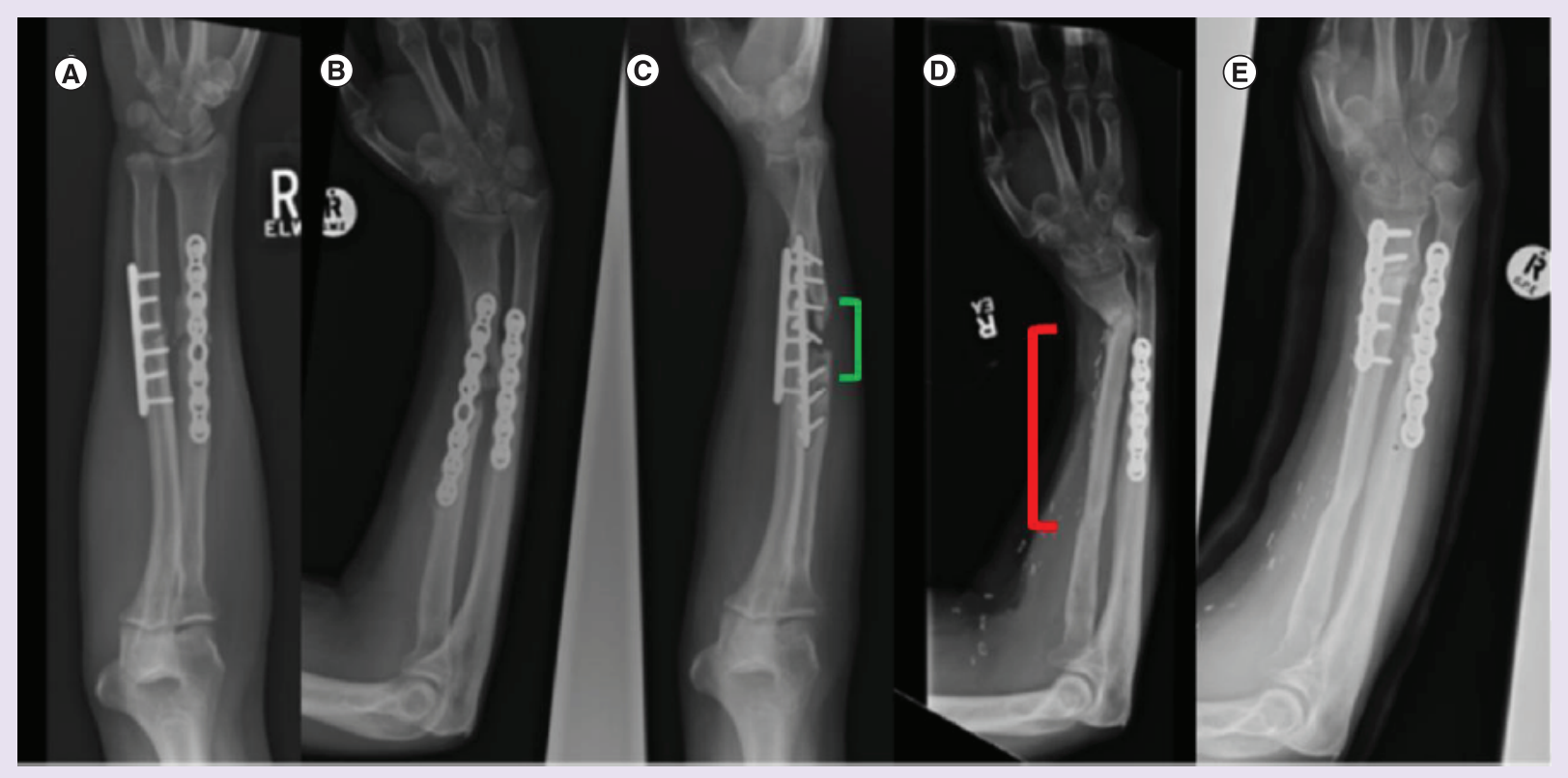

Figure 2. Vascularized fibula bone graft to reconstruct bone defect in the radius. Radiographs showing reconstruction using a fibular graft: (A) radius and ulnar fixation; (B) nonunion and deformity of the radius; (C) bone defect seen on a lateral view (bracket); (D) vascularized fibula graft used to reconstruct the defect (bracket); and (E) residual deformity at distal radius corrected with an osteotomy.

advancement of periosteal free flap has been developed in small animal studies to utilize the regenerative niche of the periosteum to functionalize decellularized bone matrix to prefabricate bone graft on a vascular pedicle that could then be transferred into a recipient site [38]. This technique has similarities to the Masquelet-induced membrane process discussed later.

Reamer-irrigator-aspirator (RIA) techniques have been utilized to harvest larger quantities of ABG from the medullary canal of long bones, as demonstrated in Figure 3. RIA graft has been found to have higher levels of gene expression associated with vascular, skeletal and hematopoietic tissues compared with ABG [39]. Furthermore, the filtrate of the irrigation has been shown to be a rich source of skeletal osteoprogenitor cells [40]. In a randomized control trial comparing ABG to RIA graft for the management of tibial nonunion, comparable results between the groups in the time to union were observed, but with fewer complications and less donor site morbidity in the RIA cohort [41]. However, the architecture of RIA graft is that of a liquid or semisolid [39] and, as such, provides limited mechanical integrity.

Allogenic graft is also widely available, although the manufacturing processes to allow simple storage and prevention of disease transmission requires removal of cellular material. This process also removes any osteoinductive capacity and can affect the mechanical properties. Tissue banks are a vital source of allogenic graft from living donors, for example, femoral head donation following total hip replacement. However, it is estimated that over $48 \%$ of potential donors are rejected following medical health screening [42]. Cadaveric samples can also be used; however, the issues regarding screening for infection or communicable disease can become difficult to manage due to the absence of an interval blood test to detect seroconversion postretrieval. Fresh-frozen allografts as well as having storage issues have been found to be potential sources of viral infection [43] and may provoke immunogenic incompatibility (reduced by washing away donor marrow) and thus, are less commonly used.

\section{Distraction osteogenesis}

An option that minimizes the need for any graft material in the management of bone tissue loss is distraction osteogenesis (DO). DO was first pioneered by Codivilla in 1905, by means of a surgical osteotomy in combination with skeletal traction to lengthen congenitally short limbs (reviewed in a re-publication in 2008) [44]. DO was further developed by Gavriil Ilizarov, practicing in Western Siberia in post-Soviet Russia, and brought to Europe 


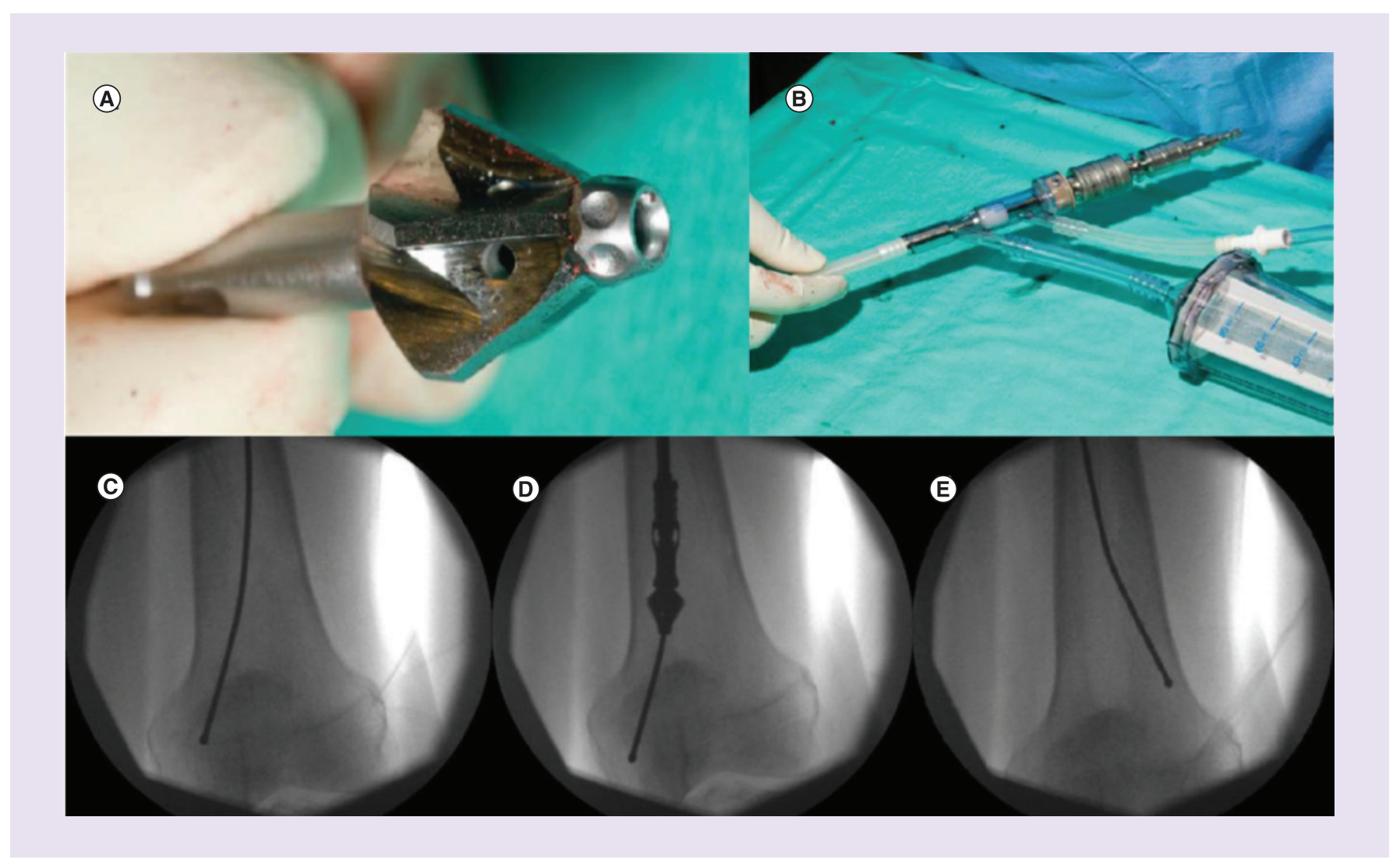

Figure 3. Reamer-irrigator-aspirator system. (A \& B) RIA equipment. (C-E) Fluoroscopic images demonstrating RIA intramedullary bone graft harvest in the distal femur over a guidewire.

RIA: Reamer-irrigator-aspirator.

in the 1980s. The optimal regimen for bone lengthening or bone transport has been well established: a stable fixation construct, an atraumatic osteotomy, a latent period to initiate the repair process, gradual distraction and a consolidation phase to allow the new bone to mature [45], as illustrated in Figure 4.

DO harnesses the regenerative capacity of bone using a mechanical stimulus and has a number of clinical indications including deformity correction, limb lengthening, management of nonunions and bone defects [46]. The development of reliable bone transport through bifocal DO has reshaped the field of limb reconstruction as large quantities of new vascularized bone, formed locally, can be generated [47]. However, DO and bone transport require lengthy treatment periods. For example, the standard regimen suggests $1 \mathrm{~mm}$ per day of transport or lengthening [48] and additional time for bone consolidation. Therefore, this technique requires a highly motivated and compliant patient cohort. Furthermore, DO has a high complication rate, with pin site infection the most common complication, which has been reported in almost every case [49]. Furthermore, docking site nonunions occur in $44 \%$ [50], often requiring further surgery with supplemental bone graft. Therefore, adjuncts to accelerate bone formation and consolidation to decrease the length of treatments would be beneficial.

In preclinical models of DO, rhBMP-2 has been used successfully, leading to significantly enhanced bone consolidation in rats [51] and even premature fusion, as the rate of ossification was faster than the distraction protocol [52]. BMP-7 has also been shown to accelerate ossification of the bone regenerate in DO [53], but these studies have not been undertaken in clinical trials. The addition of bone marrow aspirate concentrate (BMAC) and platelet-rich plasma (PRP) in conjunction with $\mathrm{DO}$ has been performed in several preclinical studies with varying results; accelerated formation of higher quality bone was observed in a canine study [54], mechanically stronger bone was found in a rabbit study [55], yet no difference was demonstrated in an ovine femoral segmental defect model [56]. In a human study, results showed that although the overall length of time in a circular frame was not reduced, there was significantly enhanced cortical healing time in the BMAC/PRP treatment group permitting 


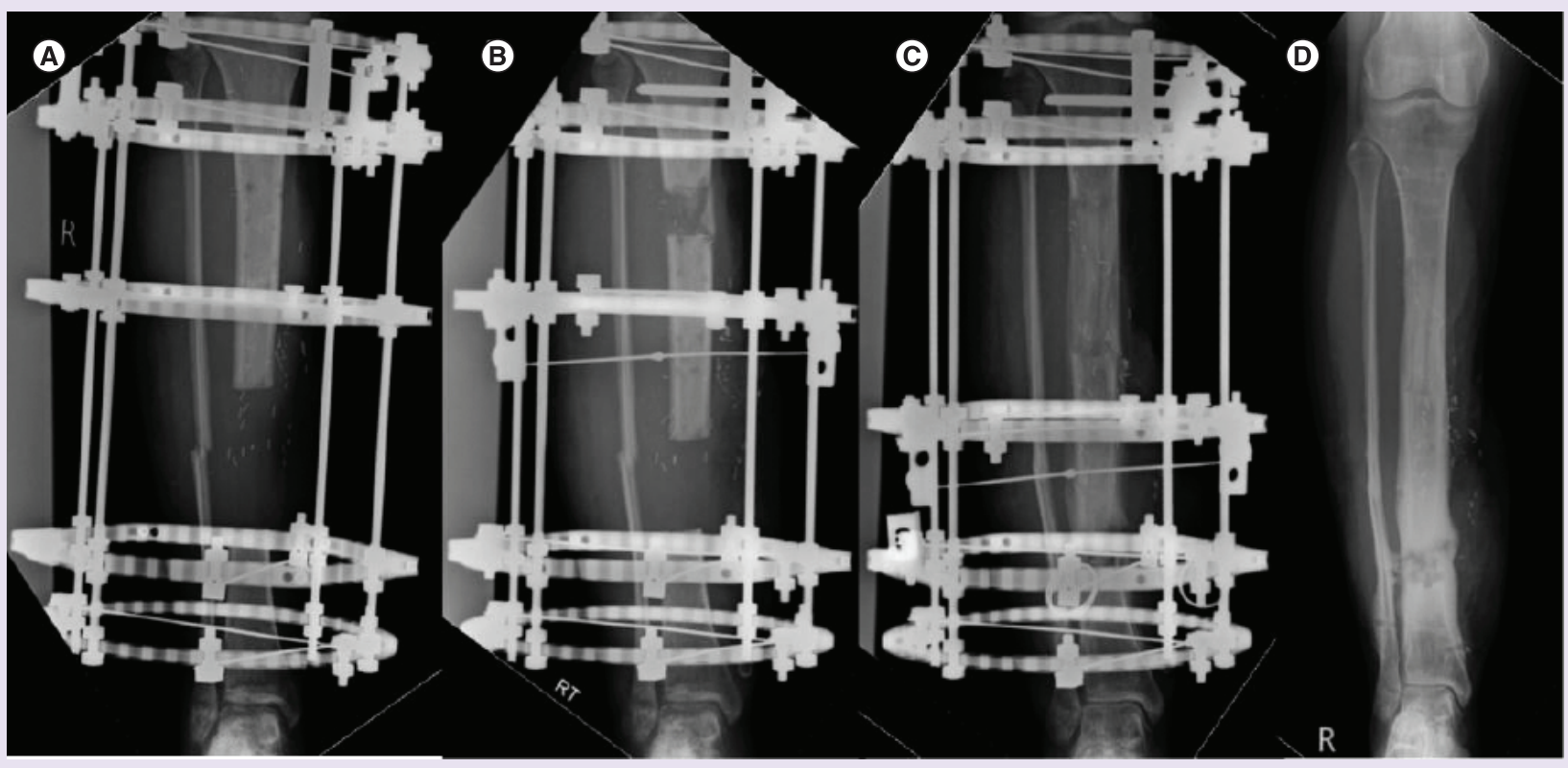

Figure 4. Bone transport through distraction osteogenesis for a tibial defect. Radiographs showing bone transport through distraction osteogenesis: (A) bone defect in the tibia; (B) proximal osteotomy to commence bone transport; (C) regenerate bone filling the defect; and (D) final outcome following removal of the circular frame.

earlier full weight bearing [57], which consequently has the additional benefit of maximizing the positive effects of full weight bearing on bone consolidation [45].

Bone transport over an intramedullary nail using an external fixator is an established technique [58], which has the advantage of reducing the time in a circular frame [59]. The disadvantages of this technique are similar to the disadvantages of treatment in a circular frame alone, which include: failed docking at the end of the transport process requiring further surgery [60]; premature consolidation [61]; and high rates of infection [59]. Importantly, there has been no significant increase in the risk of deep infection using this combination treatment method.

\section{Masquelet technique}

The Masquelet technique, or induced membrane technique, was first introduced in 1986 describing the management of diaphyseal bone defects of 4-25 cm [62], see Figure 5. Briefly, the technique involves insertion of a polymethylmethacrylate cement spacer into a bone defect and skeletal fixation, internal or external. The cement spacer provides mechanical stability and also initiates a foreign body reaction resulting in a biologically active vascularized membrane that secretes VEGF, TGF- $\beta 1$ and BMP-2 [63] and envelops the cement spacer [64]. Approximately 2 months later, the spacer is removed, while preserving the membrane, and autograft is inserted with concurrent skeletal fixation. The membrane facilitates incorporation of the bone graft to consolidate the bone defect. A meta-analysis of the Masquelet technique reported that successful bone union was achieved in up to $90 \%$ of cases; however, bone union was only accomplished following at least one additional surgical procedure in $36.3 \%$ of cases [65]. One study reported a mean number of 11.5 surgical interventions to facilitate $86 \%$ union rate in the tibia [66]. Overall, several studies have highlighted mixed results following Masquelet and unpredictable time frames to consolidation and bone union $[67,68]$.

There have been several attempts to improve the induced-membrane technique developed by Masquelet. In preclinical studies, the Masquelet technique had been assessed using synthetic scaffolds with the addition of BMP-7 and a systemic bisphosphonate, suggesting improved bone formation when all three were used compared with BMP-7 or scaffold or both [69]. However, in a clinical case series of 11 patients undergoing a Masquelet procedure with the addition of BMP-7, radiolucent changes and areas of bone resorption after 2 months were 


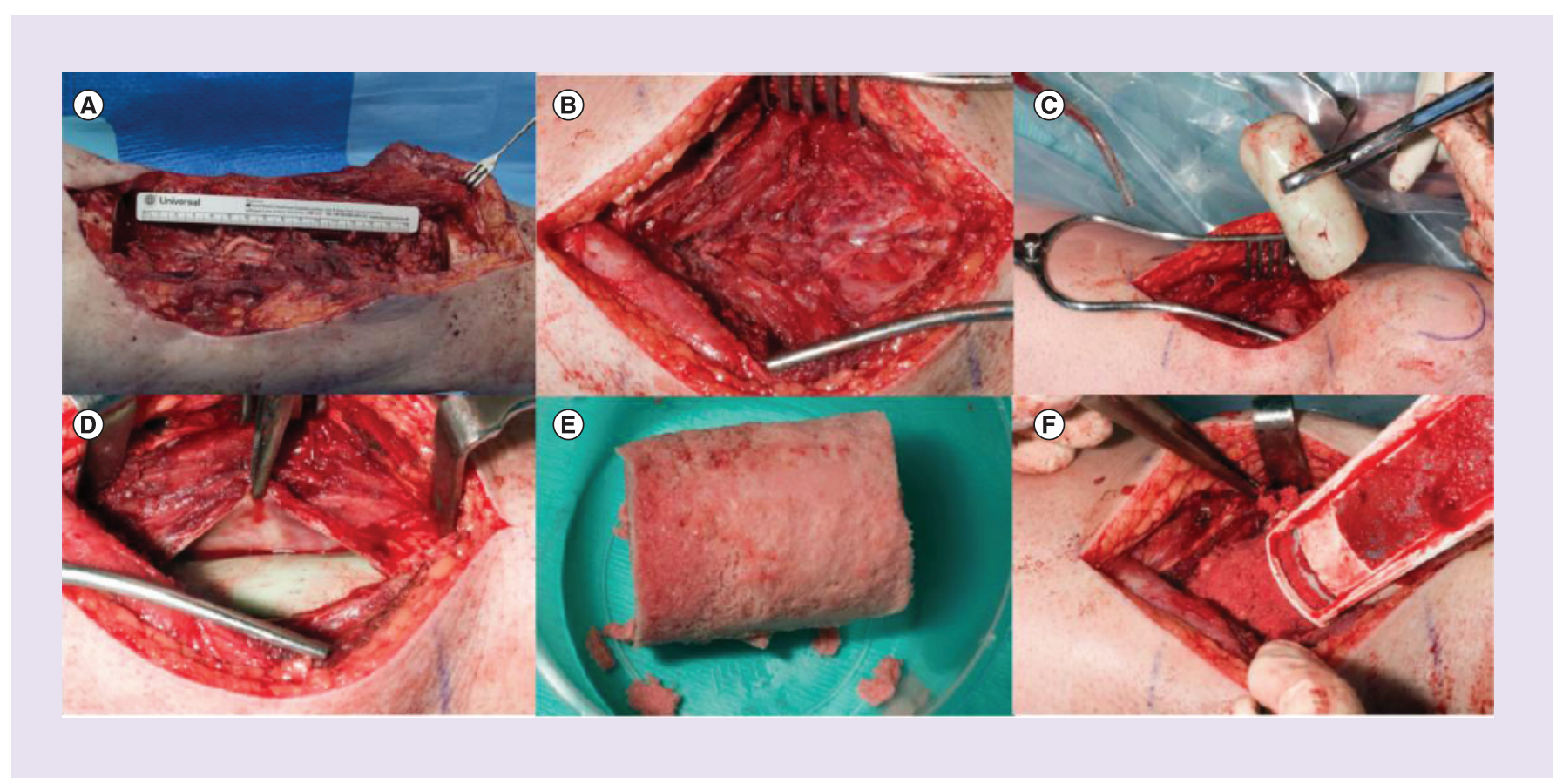

Figure 5. Masquelet technique to reconstruct a tibial defect. Clinical photographs demonstrating Masquelet technique: (A) bone defect > $15 \mathrm{~cm}$; (B) healthy wound following debridement; (C) cement spacer inserted into the defect; (D) biological-induced membrane formed around the cement spacer; (E) autologous bone graft; and (F) autologous bone graft inserted into the defect, contained by the induced membrane.

noted. This finding was markedly different to experiences prior to the introduction of BMP-7 and has led the investigators to abandon the additional application of BMP-7 [63]. Attempts to reduce the volume of cancellous bone graft required during the Masquelet procedure have also been described; a case series using absorbable gelatin sponges in the medullary canal suggested favourable outcomes [70]. As acknowledged by the authors, longer term follow-up is required and additionally a randomized control trial to compare outcomes between this new technique and standard practice would be valuable. A recent retrospective study comparing Ilizarov bone transport to Masquelet technique, for reconstruction of infected bone defects, concluded that Ilizarov methods were superior when deformity correction was required, whereas Masquelet may be preferential in short bones or in periarticular defects [71]. The number of case series reporting on the Masquelet technique are comparatively few, with each center adapting the technique resulting in a combination of different fixation modalities, different bone graft compositions and different postoperative managements leading to heterogeneous patient cohorts that are difficult to compare [68].

\section{Regenerative augmentation}

Osteogenic potential: cell-based treatments

Cellular treatment strategies that are used in orthopedics include BMAC, which contains a fraction of mononuclear cells including osteoprogenitor cells and the use of RIA systems that harvest cells from the medullary canal of long bones. Both techniques aim to harvest a population of skeletal stem cells from the bone marrow to provide an osteogenic graft material. Percutaneous BMAC injections have been used for a number of different clinical indications: tibial nonunion [72], osteoarthritis [73], avascular necrosis [74], osteonecrosis [75] and DO [57,76,77]. In a tibial nonunion case series, BMAC injection was used to obtain a union rate of $95 \%$, and an important correlation between higher colony forming unit-fibroblastic count and decreased time to union was demonstrated [72]. All of these studies aim to use the presence of skeletal stem cells to promote enhanced healing and repair; however, as these reports represent small clinical series rather than randomized control trials, their impact, to date, has been limited.

Induced pluripotent stem cells (iPSCs) are derived from adult somatic cells reprogramed to a pluripotent state [78]. The advantages of iPSCs include a personalized renewable pluripotent cell source without the ethical concerns and restrictions associated with embryonic stem cells [79]. Applications of iPSCs are varied and new concepts continue to 
emerge from this developing field, including in vitro disease modeling, drug development and organ development, which are all areas of intense research. The ability to reprogram a somatic cell creates the potential for an individual's own cells to be used for patient specific tissue regeneration and individualized treatments, which holds great interest in regenerative medicine. However, there are concerns regarding the immunogenicity of iPSCs [80], as well as potential mutations in gene expression and DNA methylation. It is thought that genetic variations that have been detected in iPSCs are due to the somatic cell itself, rather than the induction process [81]. This raises concern as the patient's cell source may contain unknown mutations that could become harmful in a clonal iPSC population. A handful of clinical cases using iPSCs exist, although, at the time of writing, none related to bone regeneration $[82,83]$.

Autologous blood derived growth factors have also been investigated in isolation, such as PDGF, and in the form of PRP. PRP contains a number of chemotactic and mitogenic growth factors to promote healing (PDGF, IGF, FGF, TGF, VEGF and EGF) [84]. There has been an increase in the number of studies and clinical trials using growth factors and mesenchymal stem cells. However, due to the heterogeneity in study design, cell characterization and reporting measures, it is difficult to draw meaningful conclusions. To rectify this, a suggested checklist has been developed to standardize reporting measures and enable comparisons across studies, which will improve evaluations of their efficacy [85].

\section{Osteoinduction: bone morphogenic proteins}

In 1965, Urist discovered a bone autoinductive agent, later termed bone morphogenic protein, crucial in bone healing and development [86]. BMPs enhance recruitment of skeletal progenitor cells and promote osteogenic differentiation by encoding a ligand of the TGF- $\beta$ superfamily, which subsequently activates the SMAD family transcription factors that regulate gene expression, potently influencing osteoblastic proliferation [87]. There are two commercially available BMP formulations that are in use in clinical practice. rhBMP-2 (dibotermin alfa; Infuse/InductOs ${ }^{\circledR}$ Medtronic BioPharma B.V., Harleen, Netherlands) and rhBMP-7 (OP-1 Implant/OP-1 Putty, Stryker, MI, USA), which are licenced for the management of open tibial diaphyseal fractures and for single level lumbar spinal fusion (www.medicines.org.uk).

Freidlaender $e$ al. found comparable results between patients treated with BMP-7 compared with autograft for tibial nonunion [88]. Further encouraging results followed the BESTT study (BMP-2 Evaluation in Surgery for Tibial Trauma), which demonstrated a significant risk reduction by $44 \%$ of secondary surgery for nonunion in the treatment cohort using rhBMP-2 in a large study of 450 patients [23]. In a clinical study comparing BMP-7 with PRP application in the treatment of long bone nonunion at various sites, BMP-7 was also found to be superior [89]. There is an on-going need for randomized control trials to evaluate the effect of BMPs as an additive agent in conjunction with other surgical techniques such as grafting with autologous bone. Most of the published literature describes small patient cohorts, without control groups, making it difficult to draw concrete conclusions.

Novel 'off licence' applications of BMPs have been reported as experimental procedures. For example, BMP-7 was applied to bone mineral blocks in conjunction with autologous bone marrow to reconstruct a mandibular defect. The BMP-7 was used to induce heterotopic bone formation within a titanium mesh case which was implanted in a patient's latissimus dorsi for maturation, followed by a subsequent successful free bone-muscle flap [90].

Although there is significant interest in the role of BMPs to augment skeletal repair and fusion, a plethora of adverse effects have been reported, which has led to concern and, subsequently, a more cautious approach to the uptake of BMPs in clinical practice [91]. The adverse effects including life-threatening swelling with airway compromise [92], heterotopic ossification [93] and osteolysis [94]. These side effects are thought to be due to the supraphysiological dose of BMP in the current preparations [91]. Therefore, techniques to localize the target area of the BMP and reduce the dose are currently areas of intense investigation [95] in order to optimize dosage and delivery.

\section{Osteoconduction: matrix \& biomaterials}

There are vast numbers of extracellular matrix products available commercially, both decellularized and cellularized. Decellularized bone matrix products can be obtained as putties, pastes, granules, powders, gels, sponges and chips, with or without carrier substances such as bovine collagen, according to the clinical scenario and surgical preference. An in-depth discussion of decellularized bone matrix products and the relevant considerations for selecting a product are reviewed elsewhere [96]. Viable allografts or cellularized bone matrix are an interesting development to offer osteogenic, osteoinductive and osteoconductive properties in a graft material. Viable allografts contain mesenchymal 
stem cells within an extracellular matrix, some with the addition of angiogenic growth factors. However, the current evidence to evaluate their use is limited to a few small case series and industry funded studies.

Given the disadvantages of autograft and allogenic grafting option, there is a clinical pressure to fabricate suitable engineered biocomposite replacements [97]. Bioactive ceramics, including hydroxyapatite, tricalcium phosphate, bioactive glass and calcium silicate, have all been investigated due to their capacity to promote bony on-growth. Hydroxyapatite is commonly used as a surface coating on orthopedic implants to enhance osseointegration. However, as materials in isolation, they are brittle and not suitable to withstand mechanical load [98], which is vital in the management of CSDs.

Three-dimensional printing of scaffold materials can create reproducible biomimetic scaffolds using a range of different materials including hydrogels, polydimethylsiloxane, polycaprolactone, polyurethane and some metals, such as tantalum or titanium custom implants. There are also exciting developments in the refinement of bioinks enabling 3D cell printing [99-101]. The limitations of additive manufacturing techniques relate to the damage to cells that occurs during the printing process, which affects cell viability and proliferation. An additional issue is the often lack of internal porosity in the materials unless specifically manufactured, which consequently inhibits the delivery of nutrients to the cells. This is increasingly relevant as the size of the material increases, moving cells further away from any nutrient source. Kang et al. present a novel technique describing an integrated tissue-organ printer that can fabricate bone, cartilage and skeletal muscle. The printed tissue contained microchannels to facilitate nutrient diffusion, which may contribute to their high cell viability (91\%) and their observation of neoangiogenesis around the printed tissue in vivo [102]. Although these approaches hold tremendous potential for the future, to date, studies are limited to in vitro and small animal in vivo investigations. As such, additive manufacturing applications are still some years from routine clinical translation as patient treatments.

\section{Conclusion}

Bone tissue loss remains a significant clinical challenge in orthopedics, impacting on a range of clinical scenarios including trauma, limb reconstruction, tumor excision and revision arthroplasty [97]. It is recognized that for optimal bone formation and bone healing four key elements, as highlighted by The Diamond Concept are pivotal: an osteoconductive scaffold; osteogenic cells; growth factors; and an appropriate mechanical environment [5]. This principle is applicable from simple fracture healing through to complex limb reconstruction strategies. A challenge within the field is a lack of robust clinical evidence in the form of randomized control trials, to draw firm conclusions with regard to specific treatment strategies for lower limb reconstruction. Critically, much of the reported literature relates to small case series, case reports and observational studies, which is understandable, given the clinical cases are rare [103]. Furthermore, the management strategies utilized often involve highly specialized procedures and usually a surgeon has preference for one particular technique due to their training exposure or surgical ethos. Thus, it remains difficult to directly compare the outcomes for each technique as there are a number of variables in play. Consequently, each patient case requires an individualistic approach rather than standardization of care.

There are several avenues of research within regenerative medicine that offer significant value to lower limb reconstruction surgery. The enhanced delivery of osteoinductive molecules within a biomimetic scaffold to improve target localization and clinical efficacy as well enhanced stem cell strategies are at the forefront for clinical translation. Furthermore, the field of orthopedics is receptive to emerging computer-based technologies, with the development of computer aided design and computer aided manufacturing to fabricate patient-specific implants, as well as custom designed instrumentation and 3D models to facilitate pre-operative planning in complex clinical cases [104106]. Bespoke titanium cages have been 3D printed to successfully salvage nonreconstructable defects $[106,107]$. Individualized $3 \mathrm{D}$ printed scaffold materials combined with bone grafting have already been successfully utilized in titanium constructs $[107,108]$. Progression of this technique using patient-tailored cellular printing methods to engineer patient-specific grafts custom designed for a specific bone defect with the capacity to provide a mechanically stable environment offer exciting new vistas to address central elements of limb reconstruction and advance the future of limb reconstruction.

\section{Future perspective}

Bone tissue loss in orthopedics is a complex clinical challenge. Bone tissue is a vascularized osteogenic environment which also provides mechanical support. Currently, there is no single engineered material that addresses all these various elements. Combined tissue engineering strategies utilizing $3 \mathrm{D}$-printed biomaterials primed with osteogenic stem and progenitor cells are an exciting prospect as these offer innovative reproducible biomaterials with the 
capacity to integrate with the host tissue. However, it is essential that any biomaterial is developed with attention to the mechanical functionality if they are to be successfully translated into clinical practice, particularly in the management of CSDs.

Lower limb reconstruction cases are rare, each with different challenges in terms of biological, mechanical and host issues. Individualized treatment strategies are required to tackle each case and this is likely to extend into the future with personalized iPSC therapy to deliver the host's own reprogramed stem cells to enhance the healing potential. Further extrapolation of individualized medicine would be through genomic profiling enabling gene targeted therapies in patients with poor biological potential.

\section{Executive summary}

Clinical need

- Trauma to a limb can result in soft tissue and bone loss.

- Reconstruction techniques have been developed to preserve limbs and avoid amputation.

- Regenerative medicine strategies are needed to augment surgical techniques and enhance bone healing.

Lower limb reconstruction surgeries

- Bone grafting and skeletal fixation is often the hallmark procedure; however, large bone defects may not be amenable to this approach.

- Distraction osteogenesis uses mechanical stress to promote bone formation over a prolonged period of time and has a high incidence of complication.

- Induced membrane Masquelet technique has shown promising outcomes; however, Masquelet requires a two-stage operation and outcomes are not reliable.

Regenerative medicine strategies

- Stem cell and growth factor therapies are gaining popularity but need standardized reporting measures to enable critical evaluation in clinical studies.

- Bone morphogenic proteins have been implemented in clinical practice to induce bone healing; however, off licence use has led to serious adverse side effects.

- Biomaterials encompass a range of scaffolds and products for bone tissue engineering. None as yet provide the ideal solution for limb reconstruction; however, 3D-printed reproducible biomimetic scaffolds with osteoinductive agents are promising.

Financial \& competing interests disclosure

Work in the authors' laboratories was supported by grants from the BBSRC (BB/L021072/1 and BB/L00609X/1) and UK Regenerative Medicine Platform Hub Acellular Approaches for Therapeutic Delivery (MR/K026682) to ROC Oreffo. The work presented here is also based on many useful discussions with past and current members of the Bone and Joint Research Group in Southampton, UK. The authors have no other relevant affiliations or financial involvement with any organization or entity with a financial interest in or financial conflict with the subject matter or materials discussed in the manuscript apart from those disclosed.

No writing assistance was utilized in the production of this manuscript.

Open access

This work is licensed under the Creative Commons Attribution 4.0 License. To view a copy of this license, visit http://creativecomm ons.org/licenses/by/4.0/

\section{References}

Papers of special note have been highlighted as: • of interest; $\bullet \bullet$ of considerable interest

1. Rhee P, Joseph B, Pandit V et al. Increasing trauma deaths in the United States. Ann. Surg. 260(1), 13-21 (2014).

2. Baker SP, O'neill B, Haddon W, Jr., Long WB. The injury severity score: a method for describing patients with multiple injuries and evaluating emergency care. J. Trauma 14(3), 187-196 (1974).

3. Boyd CR, Tolson MA, Copes WS. Evaluating trauma care: the TRISS method. Trauma Score and the Injury Severity Score. J. Trauma 27(4), 370-378 (1987).

4. Key JA. The effect of a local calcium depot on osteogenesis and healing of fractures. J. Bone Joint Surg. Am. 16(1), 176-184 (1934).

5. Giannoudis PV, Einhorn TA, Marsh D. Fracture healing: the diamond concept. Injury 38, S3-S6 (2007).

- A useful overview of fracture healing, which emphasizes the importance of mechanical stability in bone healing. 
6. Dawson JI, Kanczler J, Tare R, Kassem M, Oreffo RO. Concise review: bridging the gap: bone regeneration using skeletal stem cell-based strategies - where are we now? Stem Cells 32(1), 35-44 (2014).

- A detailed review of the evolution and clinical application of skeletal stem cell therapies in bone regeneration.

7. Perren SM. Evolution of the internal fixation of long bone fractures. The scientific basis of biological internal fixation: choosing a new balance between stability and biology. J. Bone Joint Surg. Br. 84(8), 1093-1110 (2002).

8. Claes LE, Heigele CA. Magnitudes of local stress and strain along bony surfaces predict the course and type of fracture healing. J. Biomech. 32(3), 255-266 (1999).

9. Ai-Aql ZS, Alagl AS, Graves DT, Gerstenfeld LC, Einhorn TA. Molecular mechanisms controlling bone formation during fracture healing and distraction osteogenesis. J. Dent. Res. 87(2), 107-118 (2008).

10. Schell H, Duda GN, Peters A, Tsitsilonis S, Johnson KA, Schmidt-Bleek K. The haematoma and its role in bone healing. J. Exp. Orthop. 4(1), 5 (2017).

11. Kanczler JM, Oreffo ROC. Osteogenesis and angiogenesis: the potential for engineering bone. Eur. Cell. Mater. 15, 100-114 (2008).

12. Marsell R, Einhorn TA. The biology of fracture healing. Injury 42(6), 551-555 (2011).

13. Lacroix D, Prendergast PJ. A mechano-regulation model for tissue differentiation during fracture healing: analysis of gap size and loading. J. Biomech. 35(9), 1163-1171 (2002).

14. Bhandari M, Guyatt GH, Swiontkowski MF, Tornetta Iii P, Sprague S, Schemitsch EH. A lack of consensus in the assessment of fracture healing among orthopaedic surgeons. J. Orthop. Trauma 16(8), 562-566 (2002).

15. Weber B, Cech O. Schenkelhals-pseudarthrose. In: Pseudarthro sen: Pathophysiology, Biomechanics, therapy, results. Weber BG, Cech O (Eds). Verlag Hans Huber, Bern, Switzerland, 141-179 (1973).

16. Muller ME. Treatment of nonunions by compression. Clin. Orthop. Relat. Res. 43, $83-92$ (1965).

17. Brownlow HC, Reed A, Simpson AH. The vascularity of atrophic nonunions. Injury 33(2), 145-150 (2002).

18. Reed AA, Joyner CJ, Brownlow HC, Simpson AH. Human atrophic fracture nonunions are not avascular. J. Orthop. Res. 20(3), 593-599 (2002).

-• An important paper that challenges the traditional assumption that atrophic nonunion lacks vascularity, which has significant implication for the management of nonunions.

19. Dahabreh Z, Dimitriou R, Giannoudis PV. Health economics: a cost analysis of treatment of persistent fracture nonunions using bone morphogenetic protein-7. Injury 38(3), 371-377 (2007).

20. Bhandari M, Guyatt G, Tornetta P 3rd et al. Study to prospectively evaluate reamed intramedually nails in patients with tibial fractures (S.P.R.I.N.T.): study rationale and design. BMC Musculoskelet. Disord. 9, 91 (2008).

21. Court-Brown CM, Caesar B. Epidemiology of adult fractures: a review. Injury 37(8), 691-697 (2006).

22. Giannoudis PV, Atkins R. Management of long-bone nonunions. Injury 38, S1-S2 (2007).

23. Group BS. Recombinant BMP-2 for treatment of open tibial fractures. J. Bone Joint Surg. 84-A(12), 2123-2134 (2002).

-. A prospective randomized control trial using BMP-2 in open tibial fractures, demonstrating that BMP-2 use led to a decrease in secondary interventions to stimulate healing.

24. Gopal S, Majumder S, Batchelor AG, Knight SL, De Boer P, Smith RM. Fix and flap: the radical orthopaedic and plastic treatment of severe open fractures of the tibia. J. Bone Joint Surg. Br. 82(7), 959-966 (2000).

25. Blokhuis TJ, Arts JJ. Bioactive and osteoinductive bone graft substitutes: definitions, facts and myths. Injury 42(Suppl. 2), S26-S29 (2011).

26. Janicki P, Schmidmaier G. What should be the characteristics of the ideal bone graft substitute? Combining scaffolds with growth factors and/or stem cells. Injury 42(Suppl. 2), S77-S81 (2011).

27. Giannoudis PV, Dinopoulos H, Tsiridis E. Bone substitutes: an update. Injury 36(Suppl. 3), S20-S27 (2005).

28. Arrington ED, Smith WJ, Chambers HG, Bucknell AL, Davino NA. Complications of iliac crest bone graft harvesting. Clin. Orthop. Relat. Res. 329, 300-309 (1996).

29. Cox G, Jones E, Mcgonagle D, Giannoudis PV. Reamer-irrigator-aspirator indications and clinical results: a systematic review. Int. Orthop. 35(7), 951-956 (2011).

30. Stafford PR, Norris BL. Reamer-irrigator-aspirator bone graft and bi Masquelet technique for segmental bone defect nonunions: a review of 25 cases. Injury 41, S72-S77 (2010).

31. Eward WC, Kontogeorgakos V, Levin LS, Brigman BE. Free vascularized fibular graft reconstruction of large skeletal defects after tumor resection. Clin. Orthop. Relat. Res. 468(2), 590-598 (2010).

32. Minami A, Kasashima T, Iwasaki N, Kato H, Kaneda K. Vascularised fibular grafts. An experience of 102 patients. J. Bone Joint Surg. Br. 82(7), 1022-1025 (2000).

33. De Boer HH, Wood MB. Bone changes in the vascularised fibular graft. Bone Joint J. 71(3), 374-378 (1989). 
34. Hilven PH, Bayliss L, Cosker T et al. The vascularised fibular graft for limb salvage after bone tumour surgery. Bone Joint J. 97-B(6), 853 (2015).

35. Guzzini M, Lanzetti RM, Perugia D et al. The treatment of long bones nonunions of upper limb with microsurgical cortico-periosteal free flap. Injury 48, S66-S70 (2017).

36. Haddock NT, Alosh H, Easley ME, Levin LS, Wapner KL. Applications of the medial femoral condyle free flap for foot and ankle reconstruction. Foot Ankle Int. 34(10), 1395-1402 (2013).

37. Choudry UH, Bakri K, Moran SL, Karacor Z, Shin AY. The vascularized medial femoral condyle periosteal bone flap for the treatment of recalcitrant bony nonunions. Ann. Plast. Surg. 60(2), 174-180 (2008).

38. Huang R-L, Tremp M, Ho C-K, Sun Y, Liu K, Li Q. Prefabrication of a functional bone graft with a pedicled periosteal flap as an in vivo bioreactor. Sci. Rep. 7(1), 18038 (2017).

- A promising new technique with clear translational potential.

39. Sagi HC, Young ML, Gerstenfeld L, Einhorn TA, Tornetta P. Qualitative and quantitative differences between bone graft obtained from the medullary canal (with a Reamer/Irrigator/Aspirator) and the iliac crest of the same patient. J. Bone Joint Surg. Am. 94(23), 2128-2135 (2012).

40. Porter RM, Liu F, Pilapil C et al. Osteogenic potential of reamer irrigator aspirator (RIA) aspirate collected from patients undergoing hip arthroplasty. J. Orthop. Res. 27(1), 42-49 (2009).

41. Dawson J, Kiner D, Warren Gardner I, Swafford R, Nowotarski PJ. The reamer-irrigator-aspirator as a device for harvesting bone graft compared with iliac crest bone graft: union rates and complications. J. Orthop. Trauma 28(10), 584-590 (2014).

42. Galea G, Kopman D, Graham BJM. Supply and demand of bone allograft for revision hip surgery in Scotland. J. Bone Joint Surg. Br. 80-B(4), 595-599 (1998).

43. Tomford WW. Transmission of disease through transplantation of musculoskeletal allografts. J. Bone Joint Surg. Am. 77(11), 1742-1754 (1995).

44. Codivilla A. The classic: on the means of lengthening, in the lower limbs, the muscles and tissues which are shortened through deformity. Clin. Orthop. Relat. Res. 466(12), 2903-2909 (2008).

45. Ilizarov GA. The tension-stress effect on the genesis and growth of tissues. Part I. The influence of stability of fixation and soft-tissue preservation. Clin. Orthop. Relat. Res. 238, 249-281 (1989).

46. Sailhan F. Bone lengthening (distraction osteogenesis): a literature review. Osteoporos. Int. 22(6), 2011-2015 (2011).

47. Alzahrani MM, Anam EA, Makhdom AM, Villemure I, Hamdy RC. The effect of altering the mechanical loading environment on the expression of bone regenerating molecules in cases of distraction osteogenesis. Front. Endocrinol. (Lausanne) 5, 214 (2014).

48. Ilizarov GA. The tension-stress effect on the genesis and growth of tissues: Part II. The influence of the rate and frequency of distraction. Clin. Orthop. Relat. Res. 239, 263-285 (1989).

49. Ferreira N, Marais LC. Prevention and management of external fixator pin track sepsis. Strategies Trauma Limb Reconstr. 7(2), 67-72 (2012).

50. Chaddha M, Gulati D, Singh AP, Singh AP, Maini L. Management of massive posttraumatic bone defects in the lower limb with the Ilizarov technique. Acta Orthop. Belg. 76(6), 811-820 (2010).

51. Lesaichot V, Leperlier D, Viateau V, Richarme D, Petite H, Sailhan F. The influence of Bone Morphogenic Protein-2 on the consolidation phase in a distraction osteogenesis model. Injury 42(12), 1460-1466 (2011).

52. Sailhan F, Gleyzolle B, Parot R, Guerini H, Viguier E. Rh-BMP-2 in distraction osteogenesis: dose effect and premature consolidation. Injury 41(7), 680-686 (2010).

53. Mizumoto Y, Moseley T, Drews M, Cooper IVN, Reddi AH. Acceleration of regenerate ossification during distraction osteogenesis with recombinant human bone morphogenetic protein-7. J. Bone Joint Surg. Am. 85(Suppl. 3), 124-130 (2003).

54. Dehghan MM, Eslaminejad MB, Motallebizadeh $\mathrm{N}$ et al. Transplantation of autologous bone marrow mesenchymal stem cells with platelet-rich plasma accelerate distraction osteogenesis in a canine model. Cell J. 17(2), 243-252 (2015).

55. Ali AM, El-Alfy B, Amin M, Nematalla M, El-Shafaey ESA. Can platelet-rich plasma shorten the consolidation phase of distraction osteogenesis? An experimental study. Eur. J. Orthop. Surg. Traumatol. 25(3), 543-548 (2015).

56. Hernandez-Fernandez A, Velez R, Soldado F, Saenz-Rios JC, Barber I, Aguirre-Canyadell M. Effect of administration of platelet-rich plasma in early phases of distraction osteogenesis: An experimental study in an ovine femur model. Injury 44(7), 901-907 (2013).

57. Lee DH, Ryu KJ, Kim JW, Kang KC, Choi YR. Bone marrow aspirate concentrate and platelet-rich plasma enhanced bone healing in distraction osteogenesis of the tibia. Clin. Orthop. Relat. Res. 472(12), 3789-3797 (2014).

58. Paley D, Herzenberg JE, Paremain G, Bhave A. Femoral lengthening over an intramedullary nail. A matched-case comparison with Ilizarov femoral lengthening. J. Bone Joint Surg. Am. 79(10), 1464-1480 (1997).

59. Simpson A, Cole A, Kenwright J. Leg lengthening over an intramedullary nail. J. Bone Joint Surg. Br. 81(6), 1041-1045 (1999).

60. Oh CW, Song HR, Roh JY et al. Bone transport over an intramedullary nail for reconstruction of long bone defects in tibia. Arch. Orthop. Trauma Surg. 128(8), 801-808 (2008). 
61. Mahboubian S, Seah M, Fragomen AT, Rozbruch SR. Femoral lengthening with lengthening over a nail has fewer complications than intramedullary skeletal kinetic distraction. Clin. Orthop. Relat. Res. 470(4), 1221-1231 (2012).

62. Masquelet AC, Fitoussi F, Begue T, Muller GP. Reconstruction of the long bones by the induced membrane and spongy autograft. Ann. Chir. Plast. Esthet. 45(3), 346-353 (2000).

63. Masquelet AC, Begue T. The concept of induced membrane for reconstruction of long bone defects. Orthop. Clin. North Am. 41(1), 27-37 (2010).

64. Pelissier PH, Masquelet AC, Bareille R, Pelissier SM, Amedee J. Induced membranes secrete growth factors including vascular and osteoinductive factors and could stimulate bone regeneration. J. Orthop. Res. 22(1), 73-79 (2004).

65. Morelli I, Drago L, George DA, Gallazzi E, Scarponi S, Romano CL. Masquelet technique: myth or reality? A systematic review and meta-analysis. Injury 47, S68-S76 (2016).

66. Karger C, Kishi T, Schneider L, Fitoussi F, Masquelet AC. Treatment of posttraumatic bone defects by the induced membrane technique. Orthop. Traumatol. Surg. Res. 98(1), 97-102 (2012).

67. Morris R, Hossain M, Evans A, Pallister I. Induced membrane technique for treating tibial defects gives mixed results. Bone Joint J. 99(5), 680-685 (2017).

68. Olesen UK, Eckardt H, Bosemark P, Paulsen AW, Dahl B, Hede A. The Masquelet technique of induced membrane for healing of bone defects. A review of 8 cases. Injury 46, S44-S47 (2015).

69. Bosemark P, Perdikouri C, Pelkonen M, Isaksson H, Tagil M. The masquelet induced membrane technique with BMP and a synthetic scaffold can heal a rat femoral critical size defect. J. Orthop. Res. 33(4), 488-495 (2015).

70. Cho J-W, Kim J, Cho W-T et al. Circumferential bone grafting around an absorbable gelatin sponge core reduced the amount of grafted bone in the induced membrane technique for critical-size defects of long bones. Injury 48(10), 2292-2305 (2017).

71. Tong K, Zhong Z, Peng Y et al. Masquelet technique versus Ilizarov bone transport for reconstruction of lower extremity bone defects following posttraumatic osteomyelitis. Injury 48(7), 1616-1622 (2017).

72. Hernigou P, Poignard A, Beaujean F, Rouard H. Percutaneous autologous bone-marrow grafting for nonunions. Influence of the number and concentration of progenitor cells. J. Bone Joint Surg. Am. 87(7), 1430-1437 (2005).

73. Ohgushi H, Kotobuki N, Funaoka $\mathrm{H}$ et al. Tissue engineered ceramic artificial joint-ex vivo osteogenic differentiation of patient mesenchymal cells on total ankle joints for treatment of osteoarthritis. Biomaterials 26(22), 4654-4661 (2005).

74. Tilley S, Bolland BJ, Partridge K et al. Taking tissue-engineering principles into theater: augmentation of impacted allograft with human bone marrow stromal cells. Regen. Med. 1(5), 685-692 (2006).

75. Hernigou P, Poignard A, Zilber S, Rouard H. Cell therapy of hip osteonecrosis with autologous bone marrow grafting. Indian J. Orthop. 43(1), 40-45 (2009).

76. Kitoh H, Kitakoji T, Tsuchiya $\mathrm{H}$ et al. Transplantation of marrow-derived mesenchymal stem cells and platelet-rich plasma during distraction osteogenesis-a preliminary result of three cases. Bone 35(4), 892-898 (2004).

77. Kitoh H, Kitakoji T, Tsuchiya H, Katoh M, Ishiguro N. Distraction osteogenesis of the lower extremity in patients with achondroplasia/hypochondroplasia treated with transplantation of culture-expanded bone marrow cells and platelet-rich plasma. J. Pediatr. Orthop. 27(6), 629-634 (2007).

78. Takahashi K, Yamanaka S. Induction of pluripotent stem cells from mouse embryonic and adult fibroblast cultures by defined factors. Cell 126(4), 663-676 (2006).

79. Teng S, Liu C, Krettek C, Jagodzinski M. The application of induced pluripotent stem cells for bone regeneration: current progress and prospects. Tissue Eng. Part B Rev. 20(4), 328-339 (2014).

80. Zhao T, Zhang ZN, Rong Z, Xu Y. Immunogenicity of induced pluripotent stem cells. Nature 474(7350), 212-215 (2011).

81. Yamanaka S. Induced pluripotent stem cells: past, present, and future. Cell Stem Cell 10(6), 678-684 (2012).

82. Mandai M, Watanabe A, Kurimoto Y et al. Autologous induced stem-cell-derived retinal cells for macular degeneration. N. Engl. J. Med. 376(11), 1038-1046 (2017).

83. Priest CA, Manley NC, Denham J, Wirth ED, 3rd, Lebkowski JS. Preclinical safety of human embryonic stem cell-derived oligodendrocyte progenitors supporting clinical trials in spinal cord injury. Regen. Med. 10(8), 939-958 (2015).

84. Fisher DM, Wong JML, Crowley C, Khan WS. Preclinical and clinical studies on the use of growth factors for bone repair: a systematic review. Curr. Stem Cell Res. Ther. 8(3), 260-268 (2013).

85. Murray IR, Geeslin AG, Goudie EB, Petrigliano FA, Laprade RF. Minimum information for studies evaluating biologics in orthopaedics (MIBO): platelet-rich plasma and mesenchymal stem cells. J. Bone Joint Surg. Am. 99(10), 809-819 (2017).

86. Urist MR. Bone: formation by autoinduction. Science 150(3698), 893-899 (1965).

87. Ji X, Chen D, Xu C, Harris SE, Mundy GR, Yoneda T. Patterns of gene expression associated with BMP-2-induced osteoblast and adipocyte differentiation of mesenchymal progenitor cell 3T3-F442A. J. Bone Miner. Metab. 18(3), 132-139 (2000). 
88. Friedlaender GE, Perry CR, Cole JD et al. Osteogenic protein-1 (bone morphogenetic protein-7) in the treatment of tibial nonunions. J. Bone Joint Surg. Am. 83-A(Suppl. 1), S151-S158 (2001).

89. Calori GM, Tagliabue L, Gala L, D'imporzano M, Peretti G, Albisetti W. Application of rhBMP-7 and platelet-rich plasma in the treatment of long bone nonunions: a prospective randomised clinical study on 120 patients. Injury 39(12), 1391-1402 (2008).

90. Warnke PH, Springer ING, Wiltfang J et al. Growth and transplantation of a custom vascularised bone graft in a man. Lancet 364(9436), 766-770 (2004).

91. Hustedt JW, Blizzard DJ. The controversy surrounding bone morphogenetic proteins in the spine: a review of current research. Yale J. Biol. Med. 87(4), 549-561 (2014).

92. Perri B, Cooper M, Lauryssen C, Anand N. Adverse swelling associated with use of rh-BMP-2 in anterior cervical discectomy and fusion: a case study. Spine J. 7(2), 235-239 (2007).

93. Axelrad T, Steen B, Lowenberg D, Creevy W, Einhorn T. Heterotopic ossification after the use of commercially available recombinant human bone morphogenetic proteins in four patients. J. Bone Joint Surg. Br. 90(12), 1617-1622 (2008).

94. Chrastil J, Low JB, Whang PG, Patel AA. Complications associated with the use of the recombinant human bone morphogenetic proteins for posterior interbody fusions of the lumbar spine. Spine 38(16), E1020-E1027 (2013).

95. Lee SS, Hsu EL, Mendoza M et al. Gel scaffolds of BMP-2-binding peptide amphiphile nanofibers for spinal arthrodesis. Adv. Healthc. Mater. 4(1), 131-141 (2015).

96. Shehadi J, Elzein S. Review of commercially available demineralized bone matrix products for spinal fusions: a selection paradigm. Surg. Neurol. Int. 8, 203 (2017).

97. Smith JO, Aarvold A, Tayton ER, Dunlop DG, Oreffo RO. Skeletal tissue regeneration: current approaches, challenges, and novel reconstructive strategies for an aging population. Tissue Eng. Part B Rev. 17(5), 307-320 (2011).

98. Gibbs DM, Black CR, Hulsart-Billstrom G et al. Bone induction at physiological doses of BMP through localization by clay nanoparticle gels. Biomaterials 99, 16-23 (2016).

99. Stanton MM, Samitier J, Sanchez S. Bioprinting of 3D hydrogels. Lab Chip 15(15), 3111-3115 (2015).

100. Hong N, Yang G-H, Lee J, Kim G. 3D bioprinting and its in vivo applications. J. Biomed. Mater. Res. Part B Appl. Biomater. doi:10.1002/jbm.b.33826 n/a-n/a (2017).

101. Tang D, Tare RS, Yang L-Y, Williams DF, Ou K-L, Oreffo RO. Biofabrication of bone tissue: approaches, challenges and translation for bone regeneration. Biomaterials 83, 363-382 (2016).

102. Kang HW, Lee SJ, Ko IK, Kengla C, Yoo JJ, Atala A. A 3D bioprinting system to produce human-scale tissue constructs with structural integrity. Nat. Biotechnol. 34(3), 312-319 (2016).

- Illustrates the current advances in bioprinting with clinical applications.

103. Molina CS, Stinner DJ, Obremskey WT. Treatment of traumatic segmental long-bone defects: a critical analysis review. JBJS Rev. 2(4), doi:10.2106/JBJS.RVW.M.00062 (2014).

104. Duncan JM, Nahas S, Akhtar K, Daurka J. The use of a 3D printer in pre-operative planning for a patient requiring acetabular reconstructive surgery. J. Orthop. Case Rep. 5(1), 23 (2015).

105. Esses SJ, Berman P, Bloom AI, Sosna J. Clinical applications of physical 3D models derived from MDCT data and created by rapid prototyping. AJR Am. J. Roentgenol. 196(6), W683-W688 (2011).

106. Tetsworth K, Block S, Glatt V. Putting 3D modelling and 3D printing into practice: virtual surgery and preoperative planning to reconstruct complex post-traumatic skeletal deformities and defects. SICOT J. 3, 16 (2017).

107. Hsu AR, Ellington JK. Patient-specific 3-dimensional printed titanium truss cage with tibiotalocalcaneal arthrodesis for salvage of persistent distal tibia nonunion. Foot Ankle Spec. 8(6), 483-489 (2015).

108. Kim D, Lim JY, Shim KW et al. Sacral reconstruction with a 3D-printed implant after hemisacrectomy in a patient with sacral osteosarcoma: 1-year follow-up result. Yonsei Med. J. 58(2), 453-457 (2017). 